\title{
Gamma Camera
}

National Cancer Institute

\section{Source}

National Cancer Institute. Gamma Camera. NCI Thesaurus. Code C16600.

An instrument used in medicine to produce images of internal organs after the injection of a radioactive drug into the body, where the drug releases gamma rays. It is used especially in medical diagnostic scanning. (Encarta Dictionary and Merriam-Webster Online Dictionary) 